\title{
De los libros de horas al mural de Ceutí: las flores de Ouka Leele (la tradición como clave poética)
}

\author{
Ángel Gómez Moreno \\ Universidad Complutense
}

Título: De los libros de horas al mural de Ceutí: las flores de Ouka Leele (la tradición como clave poética.

Resumen: Ouka Leele, nombre artístico de Bárbara Allende Gil de Biedma (Madrid, 1958), es autora de una obra eficaz, original y coherente. Si los dos primeros calificativos se validan de inmediato, para otorgarle el tercero hay que tomar en consideración su poética implícita y explícita, al tiempo que atender a su evolución, controlada desde la observancia de dos principios básicos: el recurso a la tradición, de la que siempre parte y a la que de retorno aporta frutos que la actualizan y fortalecen, y un control absoluto de la forma y el contenido. Le importan por igual la estética y la ética, se mueve por idéntico impulso en su obra plástica y literaria. En atención a su poemario y al mural que realizó por encargo de la localidad murciana de Ceutí, se pretende probar la verdad de este aserto.

Palabras clave: Tradición medieval, literatura y pintura, Ouka Lele.

Fecha de recepción: 27/1/2013.

Fecha de aceptación: 11/3/2013.
Title: From the Books of Hours to Ceutí's Mural: Ouka Leele's Flowers (Tradition as Poetic Key).

Abstract: In the present work we study the poems and the mural in the town of Ceutí, in the province of Murcia, by Bárbara Allende Gil de Viedma (Madrid, 1958), known by the stage name of Ouka Leele. We will prove how Ouka Leele has created -as revealed by its poetics- an original and coherent body of work, controlled by two basic principles: the recourse to tradition, a tradition she renews and strengthens; and a masterful control of form and content, in which aesthetics and ethics are inseparable.

Key words: Medieval Culture, literature and painting, Ouka Lele.

Date of Receipt: 27/1/2013.

Date of Approval: 11/3/2013. 


\section{A Bárbara Allende Gil de Biedma, en amena charla convivial.}

Como organizador del encuentro "Silos literario 2011", Basilio Rodríguez Cañada tuvo la feliz idea de invitar al cineasta Rafael Gordon para que, durante la segunda velada y a mantel puesto, presentase su documental La mirada de Ouka Leele, un alarde de pericia cinematográfica que me atrapó durante ciento quince minutos y que, a día de hoy, continúa deleitándome cada vez que lo recuerdo. Un feliz suceso potenció el sabor de este último plato: entre nosotros estaba la protagonista, la inspirada y poliédrica Ouka Leele, una artista total (recordemos que el primero en recibir este calificativo fue José Ángel Valente, aunque solo en atención a su praxis poética) a la que muchos ignaros continúan llamando -en un ejercicio reduccionista tan injusto como torpe- "la fotógrafa de la Movida”.

La metáfora de alimento con que acabo de despacharme me obliga a recordar las del último poemario de Ouka Leele, Pan de verbo (2011), cuyo título, voluntariamente anfibológico (no lo sería de haberse servido de la mayúscula en ambos sustantivos), remite a la primera de tales imágenes, aunque en puridad no lo sea. Me refiero a la ingesta de Dios a través del pan y el vino con que el cristiano lo interioriza y hace suyo, un acto que nada tiene de metafórico o traslaticio, pues define lo que justamente es. Aclararé que, en los cimientos de la fe cristiana, la gran metáfora de alimento le corresponde al Credo, que las antiguas comunidades de creyentes conocían con el nombre griego sýmbolos y el latino simbolum, que el propio Alfonso X, en sus Siete partidas, traduce como bocado.

Desde el propio título, la artista crea unas expectativas que vemos satisfechas página tras página. Frente a la carnalidad y el desgarro característicos de gran parte de la poesía contemporánea, aquí imperan una emotividad y una espiritualidad amparadas por la tradición: si con carácter general se apela a la vieja chanson de femme, que demuestra su vigencia 
estética, momentos hay en que la apoyatura se busca directamente en San Juan de la Cruz, cuyo Cántico espiritual se entreteje con versos propios en "Entrega" o "Y de muchos colores". Sanjuanianas son la noche oscura de "No hace falta", como también la música silenciosa (equivalente a "la música callada" de Cántico espiritual, est. 15) de "Tirad de mí, sí, tirad”, e incluso el vuelo de la amada en "Y ya es de noche" (que tanto nos recuerda el “AApártalos, Amado, que voy de vuelo!”, ibid., est. 13). El poeta áureo es una fijación permanente; por ello, en el epicentro de Este libro arde entre mis manos (2009), Ouka Leele reconoce abiertamente la deuda adquirida:

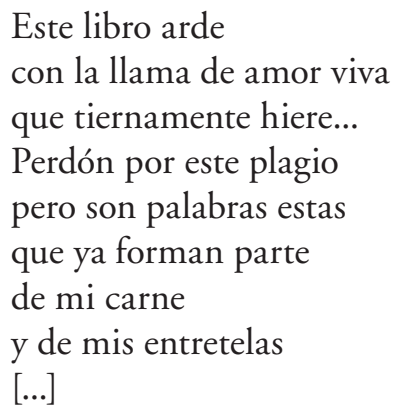

Por los derroteros que toma, la artista llega inevitablemente al Cantar de los cantares, que, siempre que se le pregunta, antepone a cualquier obra que jamás se haya escrito. Así se explica el largo tiempo que dedicó a ilustrarlo, labor recompensada luego con el Premio Nacional de Bibliofilia 2003; así, y es lo que ahora más importa, se explica la huella que deja en Pan de verbo. Al respecto, conviene estar alerta, pues el erotismo veterotestamentario lo impregna todo; por ello, aunque su título sea el mismo de la célebre novela bizantina, en "Dafnis y Cloe" se echa de menos el neoplatonismo característico del género. Algunos de los momentos más intensos caen de ese preciso lado, como la referencia a la fragancia del ser amado en "Te deseo". Al respecto, cabe notar que el Nuevo Testamento llevó esta percepción a su particular territorio e hizo posible el sintagma aroma de Cristo.

Una rebusca rápida ofrece un saldo rico de veras. En Pan de verbo nos esperan dos de los principales representantes del bestiario divino (o bestiario de Cristo, como prefería llamarlo Louis Charbonneau-Lassay en Le Bestiaire du Christ, Brujas, Desclée de Brouwer, 1940, cuya fuente 
principal está en el viejo Physiologus): el ave fénix que aparece en "Dafnis y Cloe", cuya leyenda se asoció con la muerte y resurrección de Cristo, y el pelícano de "Bebida", que, al dar la vida a sus hijos con la sangre de la herida que él mismo se inflige, obra del mismo modo que Jesús, que redimió a los hombres con su sacrificio. Aún hay que añadir un claro eco de la parábola de las vírgenes sabias y las vírgenes necias en "Barba Azul”, junto a tres oraciones convenientemente actualizadas. La primera es la estructura letánica de "Mientras me vertía", en la que el ora pro nobis se sustituye por una imprecación equivalente: "concédemelo"; la segunda (en caso de que se lea a lo divino, pues cabe también una lectura humana o temporal) es la declaración de la unidad de Dios del Antiguo Testamento: el Shemá de los judíos ("Escucha, Israel, Dios es nuestro señor, Dios es uno", Deuteronomio, 6, 4), que nos aguarda en "Solo" (título que, acaso mejor, debiera ser "Solo"); por fin, lo que tenemos en "Líbreme de la tentación, líbrame" no es sino el padrenuestro.

Ahora bien, Pan de verbo no es propiamente un poemario cristiano: lo evitan una riqueza temática que contrasta con su brevedad y una pulsión erótica que solo se aparta del amor ferino. Este último es el deseo insaciable de consumir cuerpos y más cuerpos: la pasión que arrastraba a su tío Jaime, que Ouka Leele -otra Gil de Biedma, apostilla ella- rechaza abiertamente, desde una perspectiva emocional y moral, en "El alfabeto". Hay, con todo, un elemento que vertebra o cohesiona el conjunto con toda claridad: su tono marcadamente optimista, que casa bien con la seguridad y la fuerza de sus versos. Lo curioso es que esa firmeza y ese empuje contrastan a su vez con la personalidad de la artista, modesta y calma.

La particular fórmula amorosa de Ouka Leele supone la sublimación de lo que los teóricos de otros tiempos etiquetaban como amor purus (intenso en el sentir y limitado en su carnalidad, ideal este que llega a cuajar en una rúbrica tan rotunda como "Triunfo de la castidad"), de naturaleza puramente humana. Junto a él, exentos o mezclados, se ofrecen el amor platónico (manía o locura de origen divino en la que se basa toda una teoría del conocimiento que culmina en la percepción de la idea por excelencia: la Belleza, el Bien, el Uno y, en definitiva, Dios) y el amor cristiano o caritas.

Con toda probabilidad, es el San Juan de la Cruz de "amada en el amado transformada", potenciado de nuevo por el aroma del Cantar de 
los cantares, el que brinda su soporte al motivo o idea (según su diverso desarrollo) de la fusión de los amantes en uno solo. En "Andaba perdida y en los caminos" (con un verso tan diáfano como “QQue vivas en mí no es acaso ya bastante?") Ouka Leele demuestra su vigencia y, de paso, la necesidad de llevar a cabo nuevas prospecciones fuera de los límites cronológicos en los que se mueve Guillermo Serés en La transformación de los amantes. Imágenes del amor de la Antigüedad al Siglo de Oro, Barcelona, Crítica, 1996. Cuando se rastrean las raíces de esta manera de amor extremo y se atiende a su plasmación literaria, se cae en la cuenta de que la clave está en los mismos reservorios a que recién acabo de acudir: el platonismo y el cristianismo, a los que conviene añadir también el pensamiento aristotélico.

En cualquiera de esas formulaciones, subyacen la experiencia o las experiencias amorosas concretas; sin embargo, a Ouka Leele tanto o más le importa el amor como abstracción, como motor de la vida y, en consonancia con Dante ("L'amor che muove il solle e l'altre stelle", Divina Commedia, Paradiso, XXXIII, 145), como fuerza del universo (al respecto, léase "Cloacas locas de la pobreza"). Ello la lleva a alternar, de manera harto reveladora, la mayúscula con la minúscula (amor y Amor) en "Cicatriz", un modo de proceder en el que a todos continúa marcando la pauta el inspirado Jorge Manrique. Nada importa que su código erótico sea otro, el amor cortés; sí importa, y mucho, que, entre los trovadores de toda época (y nuestros poetas cuatrocentistas forman parte de dicho grupo), el amor exista como un ideal o abstracción:
Con dolorido cuidado, desgrado, pena y dolor, parto yo, triste amador, de amores desamparado, de amores, que no de Amor.

Aunque las deudas y ecos, esto es, las marcas de la tradición se perciben por doquier, señalaré una más: el alba o aurora y su impresionante -por su amplitud y calidad- expresión literaria, con conexiones que se extienden a lo largo del espacio y el tiempo y con testigos que solo encuentran una explicación plausible en la poligénesis o generación espontánea (como demuestra el voluminoso libro de Arthur T. Hatto, Eos. An Enquiry into 
the Theme of Lovers' Meetings and Partings at Dawn in Poetry, LondresLa Haya-París: Mouton \& Co., 1965). El conocimiento de las distintas piezas de ese puzzle ilumina la invitación que se hace en "Andaba perdida y en los caminos" a que la noche se prolongue, a que no amanezca. De sus abundantes testigos cultos y populares, podría hacer no chica relación; sin embargo, aquí me basta el más conocido de todos ellos: el bolero Reloj no marques las horas.

En su aproximación a la naturaleza, Ouka Leele cuenta con idénticos basamentos. El platonismo asiste al cristianismo en su plasmación de una naturaleza perfecta, reflejo a su vez de la perfección del Hacedor, como leemos en fray Luis de León, empapado en el pensamiento platónico tanto por su condición de agustino como por el preciso momento que le tocó vivir. Recordemos, por ejemplo, que, entrado el siglo XVI, la fórmula del Pietro Bembo en Gli Asolani (1505), donde cruzó petrarquismo y platonismo, ya había calado en la literatura europea. En algunos casos, sospecho que el poeta de Belmonte es la clave primera de algunas composiciones, como en "Teorema de la Unidad", en que la perfección de la naturaleza remite en definitiva a Dios. Retengamos la imagen de fray Luis en su retiro de La Flecha y la larga retahíla de autores áureos que apelaron al tópico del menosprecio de corte y alabanza de aldea, aunque no radique en ellos la clave; de hecho, estoy plenamente convencido de que el amor de Ouka Leele por el campo y su rechazo de la ciudad (léase a este respecto "Sobre la memoria y la materia") tienen todo que ver con el recuerdo de una infancia feliz en la casa serrana de San Rafael. De que estoy en lo cierto me da la razón la propia artista en La mirada de Ouka Leele.

De todos modos, si tuviera que aducir algún precedente literario para esa doble tendencia, sin dudarlo apelaría al Federico García Lorca de Poeta en Nueva York (1929-1930); ya puesto, luego calaría hasta Rubén Darío, allí donde plasma su rechazo de esa ciudad (la ciudad moderna por excelencia) por medio del oxímoron amor y dolor. El célebre comienzo de La gran cosmópolis (Meditaciones de la madrugada) no puede expresarlo más claramente (1914):

Casas de cincuenta pisos, servidumbre de color, millones de circuncisos, máquinas, diarios, avisos 


\section{y... ¡dolor, dolor, dolor!}

Solo me resta añadir que, a día de hoy, poco es lo que queda de la urbanita de su primera época, de aquellos ya lejanos años en que no solo ella sino la mayoría de la juventud madrileña y española, y con ella sus artistas favoritos, cantaban a la ciudad en abstracto (Mecano y "Quiero vivir en la ciudad") o a Madrid en particular (Joaquín Sabina y "Pongamos que hablo de Madrid"), sobre todo al Madrid más golfo y nocherniego. Tampoco se perciben restos apreciables del neofuturismo de aquel momento, que recuperó una de las señas de identidad de las Vanguardias y la sublimó en los formatos más diversos (hasta dar en la estética y el léxico neofuturistas del programa infantil titulado La bola de cristal, presentado por Alaska, cuyo éxito prolongó esa fórmula hasta bien entrados los años noventa).

Hoy, por el contrario, Ouka Leele se deleita en la naturaleza más pura, en que halla el trasfondo idóneo para la expresión de sus sentimientos. Esa elección le aporta, de paso, el valor añadido que supone la tradición, que ella revisa en profundidad y remoza, aquí y allá, donde y cuando más le conviene. Tenemos, sí, el hortus clausus o conclusus de la poesía amorosa de todos los tiempos ("Aqueste huerto", penúltima de sus perlas en prosa o "Cuentitos"), pero de él solo queda el ruiseñor amante; por lo demás, si la flora se resuelve en una sola alusión a la orquídea (luego me ocuparé de esta especie), la fauna de este locus amoenus, con unos delfines imposibles y unas anguilas inusitadas en un vergel, cae dentro de lo que los clásicos llamaban adýnata en griego e impossibilia en latín. ¿A qué responde tan profunda alteración de sus componentes?

A esta pregunta se le encuentra rápida respuesta cuando se toman en consideración los profundos retoques que Ouka Leele ha dado a tan añosa y subyugante imagen. El huerto ya no es lugar de encuentro de los amantes, como tampoco alude, de modo más o menos velado, al receptáculo femenino (como en algunas composiciones tradicionales de lo más atrevido, a la manera de "No entres en huerto ajeno, / que te dirá mal su dueño; / no entres en huerto vedado, / que te dirá mal su amo"). El epíteto salvaje (inesperado, toda vez que el hortus es, frente a la silva, un lugar domeñado por la mano del hombre) pone sobre aviso al lector, prepara para todo lo demás: el huerto es ahora la pasión encendida, con componentes que oscilan entre lo esperado y lo admirable, y con un 
guiño sagrado que intensifica el manierismo de la composición y estrecha los lazos con el resto del libro. Leamos:

Oleadas del salvaje huerto que llevo dentro... Noli me tangere... allí crecen delfines alegres y anguilas como las flores... Flechas y cascabeles, a veces alguna orquídea y cantan sagrados, los ruiseñores.

De los árboles frutales, solo aparece uno, aunque bien conocido por el erotismo que comporta: el granado, milgrano (así se le llama en el prólogo de los Milagros de Nuestra Señora de Berceo, que resulta ser una alegoría mariana) o milgranar (así lo leemos en la anónima Razón de amor). Son las "dulces granadas" de "Dafnis y Cloe", el fruto con que Lucas Cranach, muy significativamente, ambienta la transacción comercial entre un viejo rijoso y una prostituta en El pago (1532, Museo Nacional de Estocolmo). Junto a la granada, abierta para que se vean bien sus granos de color rojo intenso (o de color granate, para estrechar los lazos con su familia léxica), el artista incluye tres animales lascivos: unas perdices en su percha, un ánade colgado y la cornamenta de un ciervo (de todo ello me ocupo en "La flora entre los primitivos y Cranach, de Razón de amor a Cervantes: paisaje, exégesis y poética”, Edad de Oro, 30 [2011], pp. 127-166). Huelga añadir que, en este universo de referencia, los entrecruces sacro-profanos son continuos, como vemos en el Botticelli de Madonna della melagrana, datado ca. 1487 (Galleria degli Uffizi, Florencia).

Mucho más apegada a la tradición se revela la artista al otorgarle al agua la dimensión erótica que en justicia le corresponde, sobre todo cuando el escenario lo ponen las orillas de un río, como en "Ribera". El lugar, marco idóneo para el encuentro amoroso o para una imagen galante, resulta recurrente tanto en la lírica cortesana (por ejemplo, en "A las riberas de un río" de Pedro González de Mendoza") como, y sobre todo, en la lírica tradicional (por ejemplo, en "Pela ribeira do rio" de Johan Zorro). Desde ambos veneros, y particularmente desde el segundo, llegamos a la conocidísima "La casada infiel” de Federico García Lorca. En esa tradición, y con más razón al tratarse de agua, bebe Ouka Leele, cuya breve composición (primero de los siete micro-relatos de la sección "Cuentitos") reza así: 
Vino, y de la mano la condujo hasta el río. En la orilla, peces de plata buscaban sus ojos. Él los vio callado; ella iba con los ojos cerrados y no supo que la miraban. No pudo dar a los peces lo que buscaban.

También encaja en la tradición el viento fértil, capaz de empreñar yeguas y perdices, particularmente si sopla desde el lugar en que se encuentra el macho; es el viento juguetón que levanta las faldas de la joven en el poemario tradicional castellano, el mismo que agita su camisa tendida o su cabello en las cantigas de amigo gallego-portuguesas; desde él, y sin solución de continuidad, llegamos a "Preciosa y el aire" de García Lorca (para todo ello, véase mi trabajo "La perdiz en la literatura, el folklore y el arte: a propósito de una charla sobre Brunetto Latini”, en Cuadernos de Filología Italiana. Homenaje a Angel Chiclana Cardona (Madrid, Universidad Complutense, 2000], vol. I, pp. 85-98). Solo tras estas puntualizaciones podemos sacarles el jugo a dos momentos de su poemario: "Del lado del viento llega tu sonido inocente" y "la caricia del viento que me ruboriza / y me trae tu recuerdo", que leemos, respectivamente, en "Dafnis y Cloe" y en "Te deseo". Aunque podría pasar revista a algunos elementos más, ya solo me ocuparé, y al final de este trabajo, de la flora de Ouka Leele, en la que cabe hablar también de una tradición renovada, aunque de tradición propiamente se trata al fin y al cabo.

Ouka Leele, por principio, rechaza las manifestaciones extremas de dolor y patetismo, el sentimiento dramático de la existencia o la poética de lo feo. Si ha logrado escapar a la carnalidad y el desgarro extremos, tan frecuentes en la lírica actual, es porque su palabra, su paleta y su objetivo tienen su trasfondo en esa infancia feliz a la que acabo de referirme, de la que da buena cuenta en distintos momentos de La mirada de Ouka Leele. Tanto o más importa su confianza en que una mano buena rige el curso de las cosas: es la Providencia, a la que tan importante papel cupo en el pasado, que aparece diáfana en "No hace falta". No es de extrañar, por ello, que el mensaje de "Lo diario" recuerde tanto al "Beato sillón" de un Jorge Guillén plácidamente instalado en esta vida.

En último término, el optimismo que derrama la obra de Ouka Leele se debe a una atmósfera feérica característicamente suya (con brujas buenas, como en "Nigredo", con cálices que traen aromas del roman courtois a lo divino, con hechizos y con dragones que devoran doncellas), idónea para 
expresar los mejores sentimientos y refractaria a toda manera de ansia o deseo desmedido de poder, de riqueza, de placer o de una fama ante la que, en principio, sucumbe todo artista. Como bien sabemos, esta es la misma fórmula de fray Luis de León, su escondida senda o secretum iter, que parece corresponderse, punto por punto, con el secreto de los secretos de "Dafnis y Cloe" (como estoy seguro de que la artista desconoce el pseudoaristotélico Secretum secretorum, tan solo señalaré la que tengo por curiosa coincidencia). También hubo santos que huyeron de la fama por el peligro que esta tiene siempre de degenerar en soberbia o vanagloria; para ello, hubieron de poner tierra por medio y marchar a lugares donde no los conocía nadie. Algo así cabe ver en Bárbara Allende Gil de Biedma, camuflada tras el nombre artístico de Ouka Leele. Al respecto, un poema, "Raíl de vanidad", compendia su particular hoja de ruta, su arte de marear la vida.

En esa (auto)imposición de un nuevo nombre, nuestra inspirada artista coincide, en la ficción pura, con los héroes de la novela de caballerías medieval y renacentista. Basta el ejemplo de Amadís de Gaula, primero llamado Doncel del Mar y conocido luego como Beltenebros, Caballero de la Verde Espada o bien Caballero del Enano (para quien lo precise, recordaré que Alonso Quijano se da nombre de Don Quijote y luego recibe el de Caballero de la Triste Figura y Caballero de los Leones). En el mundo real, el modelo básico lo brindan aquellos hombres y mujeres que inician una nueva vida en comunidad en algún cenobio; no obstante, el arte ofrece esa misma posibilidad a lo largo de los siglos, como vemos en los casos de El Greco o El Veronés en la pintura áurea y de tanto y tanto dibujante desde las Vanguardias para acá. Sin salir del círculo de Ouka Leele, me basta un ejemplo doble: el de El Hortelano (José Alfonso Morera Ortiz) y el de Ceesepe (Carlos Sánchez Pérez).

Si Pan de verbo tiene mucho de obra cristiana, con más razón debe considerarse un poemario moral, pues no hay una sola composición que no lo sea propiamente. El tono admonitorio es especialmente intenso en determinados lugares, como en "Lección de paciencia", que es exactamente eso, o en "Derrocada apariencia", donde el rechazo de la mentira por parte del poeta conecta con una larga tradición. De todos los referentes que se me ocurren, el más poderoso está en Petrarca, cuyas Invective contra medicum guardan la mejor defensa imaginable de la ficción como 

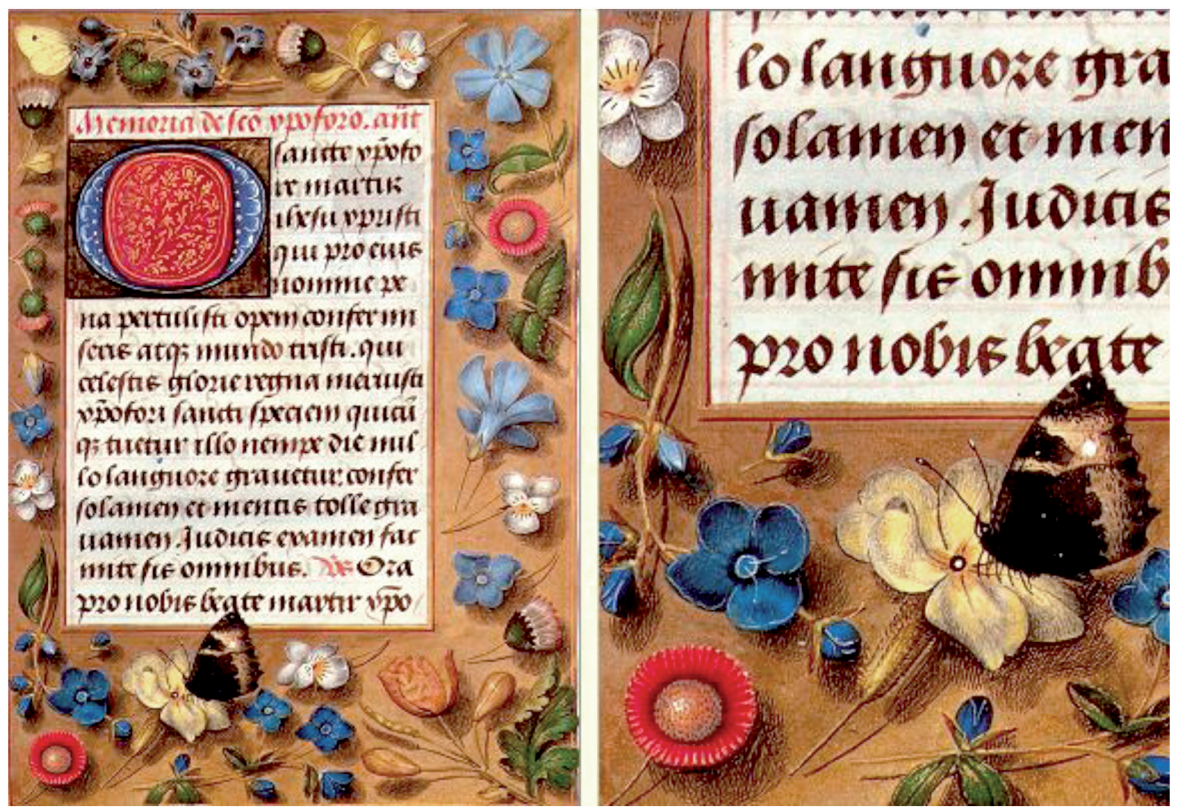

Libro de horas de Hastings (Flandes, ca. 1480, British Library, Add. Ms. 54782).

[Especies: vinca, hiedra terrestre, verónica, margarita, prímula, vellosilla y celidonia mayor.]

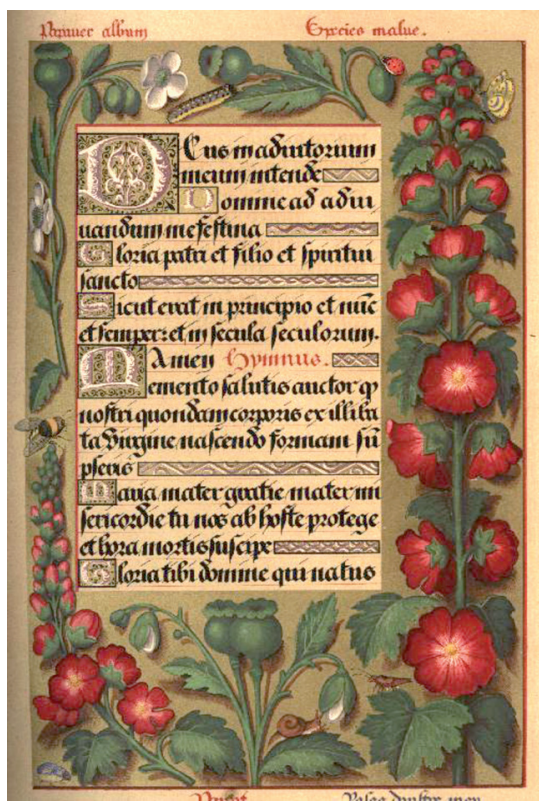

Libro de horas de Ana de Bretaña (Francia, 1508, Bibliothèque Nationale, lat. 9474).

[Especies: malva y adormidera.]

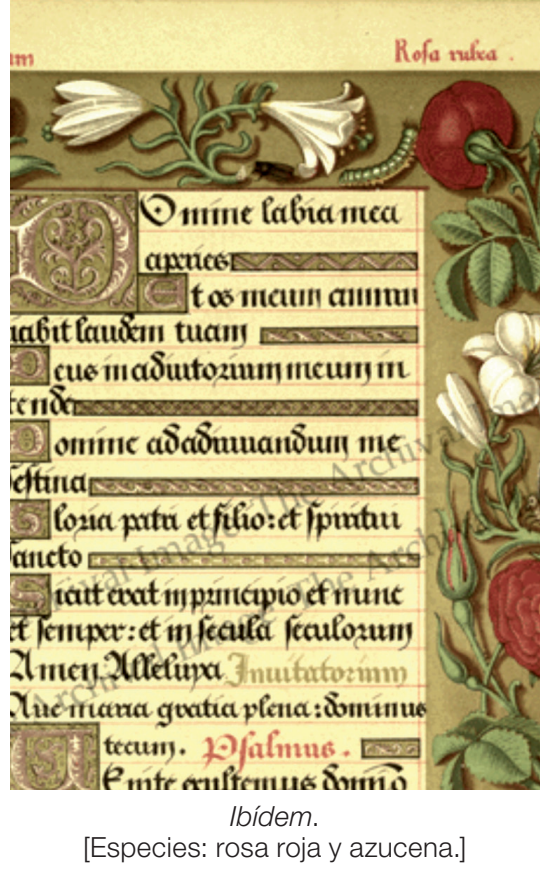




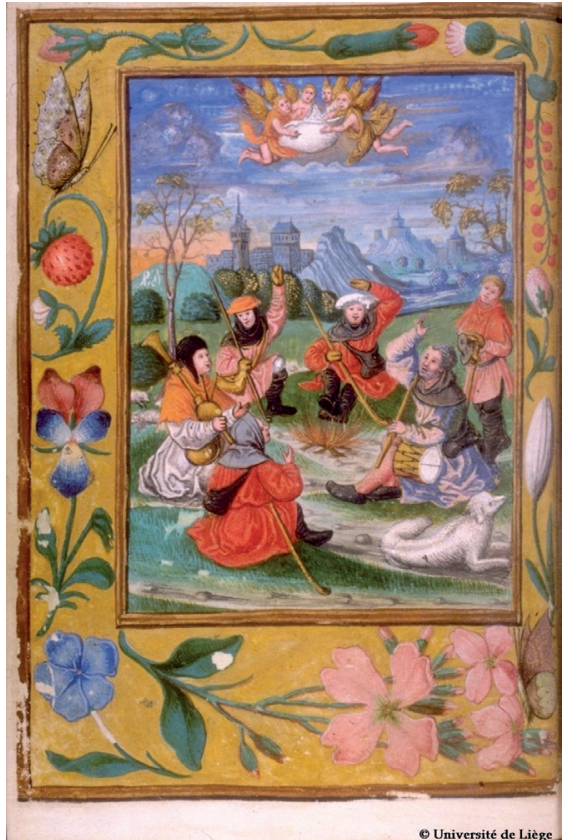

Libro de horas de Gérard van der Stappen

(Flandes, comienzos del siglo XVI, Biblioteca de la Universidad de Lieja, ms. 3591).

[Especies: violeta tricolor, vinca, cólquico, fresa, grosella y hierba de San Antonio.]

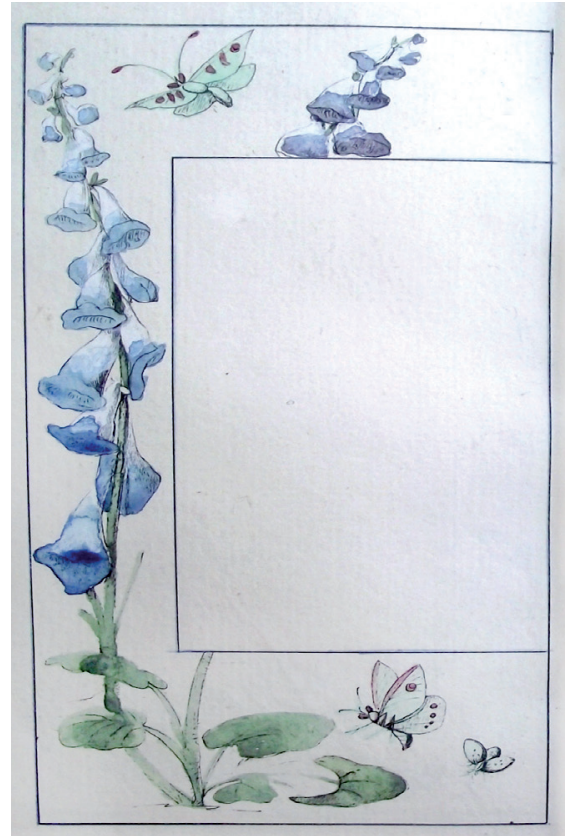

Madame C. Mermet y Madame I. Mermet, Missel de Première Communion et de Mariage (Biblioteca de Ángel Gómez Moreno, ms. s. s., 1889).

[Especies: digital o dedalera.]

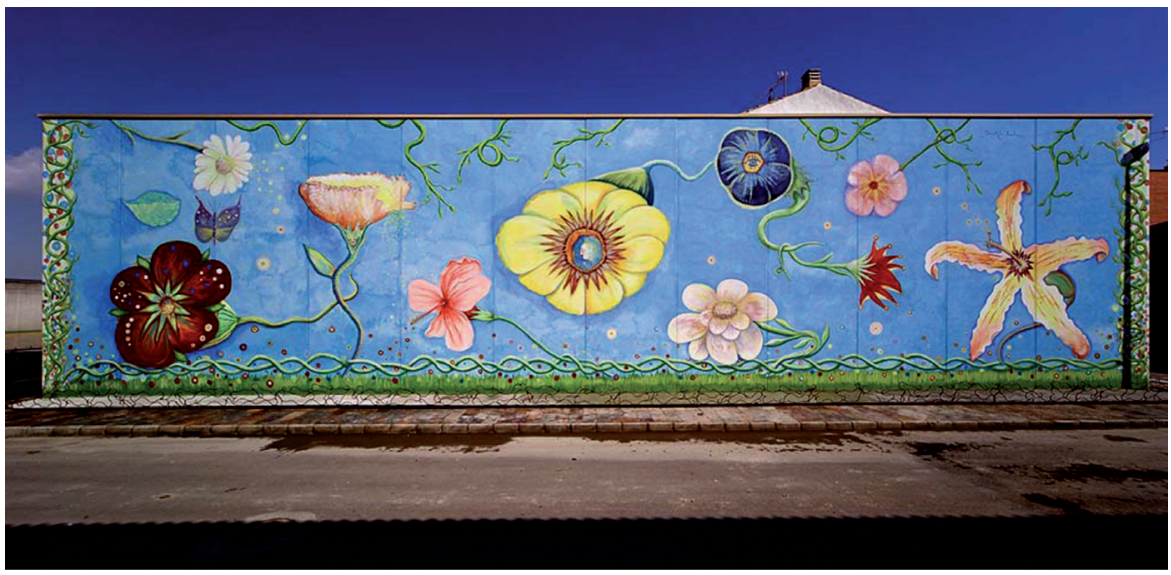

Ouka Leele, Mural (Ceutí, Murcia, 2008). 
recurso, un procedimiento que nada tiene de mentira o de engaño. Los poetas fingen, dice Petrarca, o lo que es lo mismo hablan de forma velada, lo que solo quiere decir que se sirven de un velo o integumentum, término y concepto que no faltan en el metalenguaje artístico de Ouka Leele; así, en un momento de "Tirad de mí, sí, tirad”, define su lucha con las palabras y particularmente con los colores del modo siguiente:

Traspasar el velo quiero para penetrar lo mudo

buceando estallante de amarillos y fucsias,

en el ocre, un verde

circundado por los rayos de la luz a su lado.

[...]

He levantado la esquinita de ese velo

y al otro no había palabras, no.

Lo principal, no obstante, se compendia en "Hastío de voces", donde indica cómo ha de leerse el conjunto del libro: "no amor, no llanto, no sexo, no declamación aburrida. / Tampoco vómitos, desde luego". Como he dicho, Ouka Leele prefiere la contención de ánimo y palabra, la supresión de todo exceso y la vuelta a un valor literario otrora fundamental: el decoro. La artista persigue, eso sí, activar esa especie de resorte que todos llevamos en nuestro interior, algo que logra al inducir asombros, inquietudes y hasta sobrecogimientos. En ese terreno, su seguridad es absoluta, pues sabe bien lo que quiere; en cambio, en "Streaptease del verso" (uno más de sus "Cuentitos"), nos habla de la liberación de la métrica y la retórica. ¿Es lo que siente de veras? Sospecho que es así solo a ratos, pues a esa declaración de principios se añade luego su fascinación confesa por los grandes poetas del pasado, que manejaban ambas ciencias literarias (la que lleva a domeñar el metro y la que logra otro tanto con la palabra) a su antojo.

La obsesión por el color no merece mayor comentario, ni siquiera cuando se recurre a la palabra, y no al objetivo o la paleta. En versos como los recién citados, cabe hablar, en mi opinión, de una hiperestesia que nada tiene de patológica (a diferencia de Joaquín Mir), una percepción especialmente marcada entre los pintores y literatos levantinos, como Joaquín Sorolla y Gabriel Miró. En ese sentido, la moralidad no supone limitación alguna para el artista: ni impone gamas de grises, ni tampoco fuerza fórmulas 
prosaicas; más aún importa retener que en ningún caso debe verse en ella el envés de la alegría, la belleza y el placer. En este preciso sentido, la poética de Ouka Leele es absolutamente original, incluso revolucionaria; y lo es porque conecta con la tradición y, sin necesidad de subvertirla, le aporta nueva savia. Así ocurre cuando, con indudable valentía, retoma un tema del que Occidente entero parece haber renegado: la muerte.

Desde el Medievo, la muerte tiene una doble plasmación, plástica y literaria, que halla su máxima expresión en las Danzas de la muerte o Danzas macabras, que, en España y en Europa, se transmitieron a modo de texto o imagen. Ocasiones hay, y no pocas, en las que ambos coinciden, como en los libros de horas impresos a finales del siglo XV y comienzos del siglo XVI, en que la composición, en latín o en lengua vernácula, se acompaña de escenas, a modo de ladillos, a cargo de artistas de renombre, como el gran Hans Holbein. En el caso de Ouka Leele, contamos también con esa doble dimensión, plástica y literaria; además, el mensaje coincide en lo fundamental, toda vez que la tradición la ampara en ambos casos. Así, en "Intersticios", nos encontramos con la Muerte triunfante, democrática e igualadora del citado Holbein, la misma de Brueghel el Viejo y Matthaeus Merian.

La imaginación no tiene problemas en darle forma, con su "salvaje melodía”, sus peculiares instrumentos de percusión y viento ("Mi flauta es vuestro hueso") y, lo más determinante, la orden final a la que ningún mortal puede escapar (entre las leyendas más comunes de que se acompaña el esqueleto, con su arco, flechas y guadaña, está el Nemini parco qui vivit in orbe): "Danzad conmigo, levantaos, ¡vamos!”. Por descontado, ese final desvela su deuda respecto del Romance del enamorado y la muerte, que concluye: "Vamos, el enamorado, la hora ya está cumplida".

Lo formidable es que Ouka Leele, en consonancia con esa larga tradición, de la que me ocupo con más detalle en otro lugar (en que, entre otras cosas, comento su magnífico cuadro Hasta que la muerte nos una, de 1988), esquiva el tremendismo; del mismo modo, en un momento de La mirada de Ouka Lee, la artista habla de la muerte con naturalidad y hasta se atreve a calificarla de "maestra", en consonancia con la figura que apostrofa a los mortales y les pide valentía cuando más la precisan (y tengo en mente el parlamento de la muerte a don Rodrigo Manrique en las Coplas de su hijo Jorge, que arranca, en un tono más admonitorio 
que conminatorio, con aquello de "Buen cavallero, / dexad el mundo engañoso / e su halago. / Vuestro coraçón de açero / muestre su esfuerço famoso / en este trago").

En ese otro trabajo (correspondiente a una ponencia que daré en la Universidad de Alicante en octubre de 2011, en un congreso sobre hagiografía), sigo la línea que atraviesa y hermana las distintas épocas de Ouka Leele, entre los ochenta y el presente, entre Madrid (1984) y Santa Bárbara (2011), vale decir, entre un en apariencia recalcitrante laicismo urbanita y el cultivo abierto del género hagiográfico. Ahora me conformo con poner nuevamente de relieve el peso de la tradición, que confiere primero y fortalece luego las señas de identidad del libro de poemas que me ha servido de introito. Los referentes a los que apela son artística y literariamente linajudos: entre destellos mitológicos (con la leyenda de Orfeo y Eurídice) y dantescos (con Virgilio como guía en el Decessus ad inferos), obvios unos y otros en el poema titulado "Sí”; entre la lírica tradicional (ya he aludido a la chanson de femme) y la modernidad más rompedora; entre las formulaciones manieristas más complejas (algo particularmente evidente en su obra plástica) y la esencialidad del haiku y otras formas de la lyra minima.

Por lo demás, he puesto de relieve la fuerte impronta que fray Luis y más aún san Juan de la Cruz dejan en Ouka Leele, una marca que la artista jamás ha ocultado. Si de detectar intertexualidades se trata, percibo nítida la técnica paisajista de Antonio Machado (como en "Paisaje en otoño desde el coche" y "Maletas de alegría", composiciones ambas de gran plasticidad), junto a ecos de Rafael Alberti (así en "A los infinitos ángeles alados", verso de "Y de muchos colores") y hasta toques marcadamente modernistas del tipo "pelusas de odaliscas y ungüentos davídicos", "artífices efímeros". Estas dos citas me obligan a recordar, aunque sea a vuelapluma, que la acumulación de esdrújulos o proparoxítonos resulta extraña al oído de un hispanohablante y que, al servirse de él, los artistas suelen perseguir una finalidad cómica o satírica, como Joan Manuel Serrat en su célebre "Es esa muchacha típica” (Mi niñez, 1970).

Que su uso con ese fin no es privativo de la lengua española (que cuenta con numerosos ejemplos de justa fama, como cierto pasaje de La venganza de don Mendo de Pedro Muñoz Seca) se comprueba en un poema satírico latino del siglo IX procedente de Verona: el famoso Andecavis abbas esse 


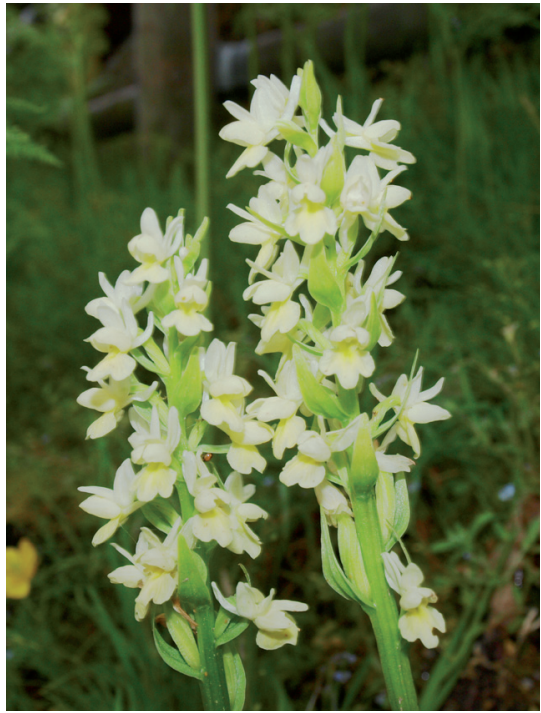

Dactylorhiza insularis (orquídea pálida).

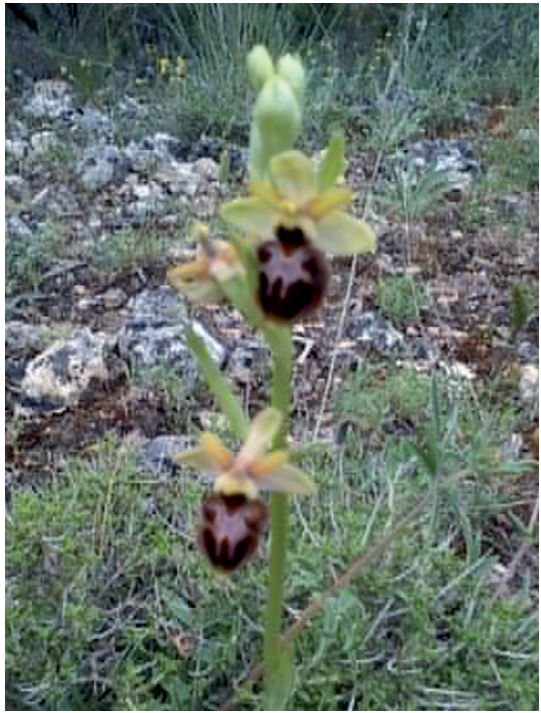

Ophrys fusca (orquídea abeja negra).

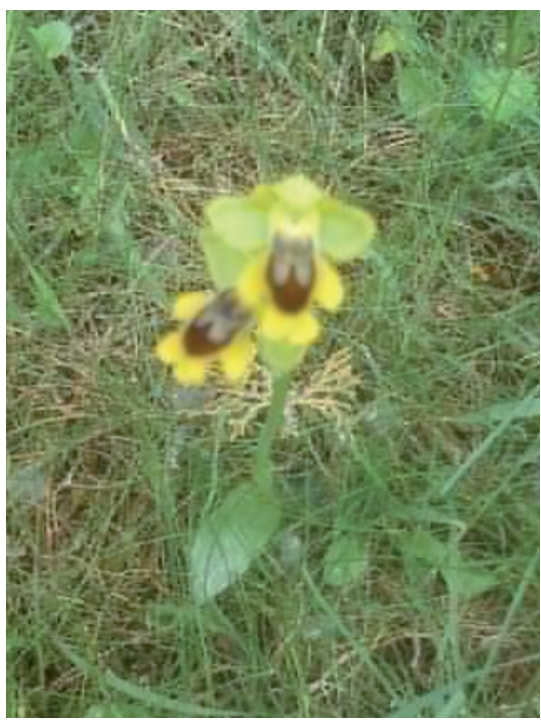

Ophrys lutea (orquídea abeja amarilla)

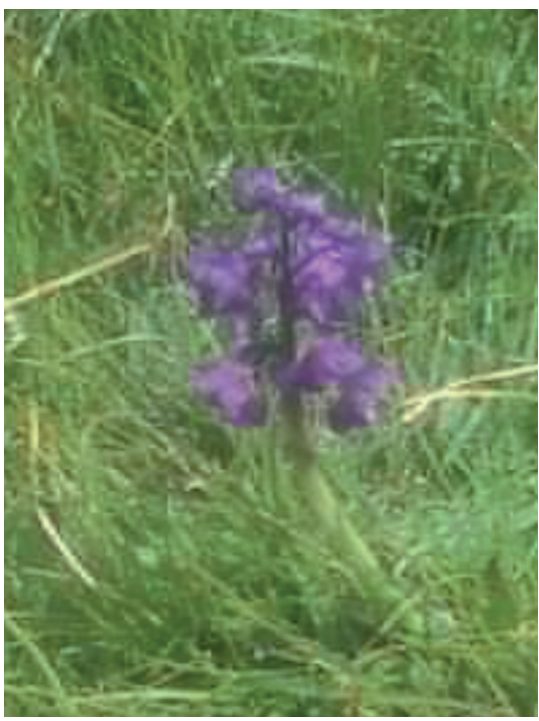

Orchis morio (satirión o testículo de perro) 


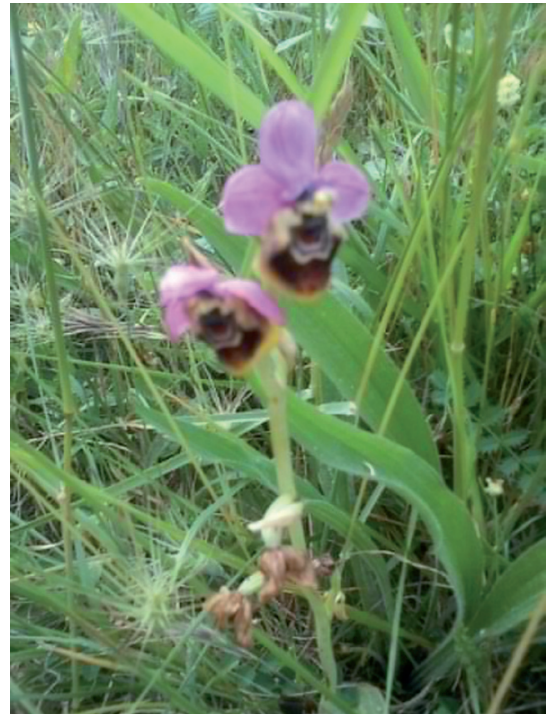

Ophrys tenthredinifera (orquídea de avispa)

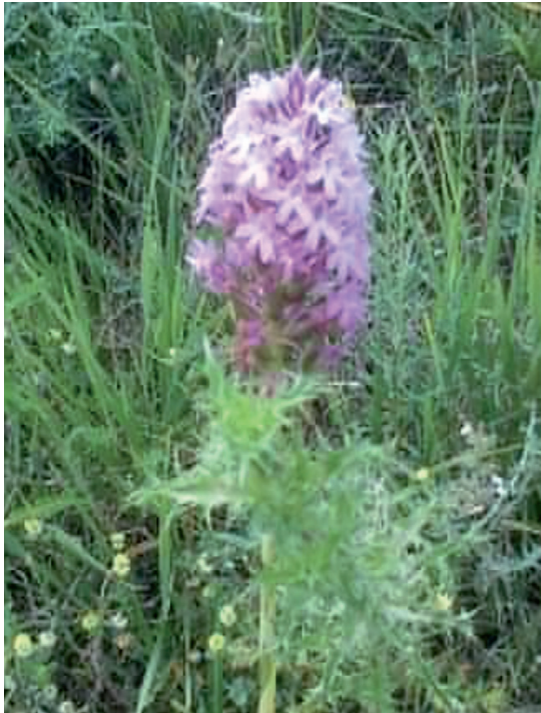

Anacamptis pyramidalis

(orquídea piramidal)

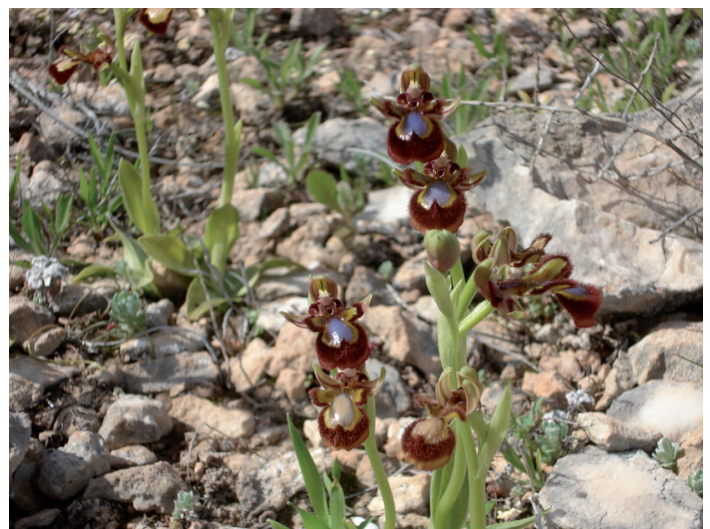

Ophrys speculum (orquídea abeja espejo) 
dicitur, cuyos versos acaban todos con una palabra esdrújula. Mordaz, cáustica, pero también sobrecogedora, y en ningún caso cómica, resulta la canción de Chico Buarque que da nombre a todo un disco: Construção (1971). Lo que más importa es que Ouka Leele, a lo largo de su fértil y ya larga vida artística, se ha servido del esdrújulo con diversos propósitos: unas veces con la memoria puesta en los cisnes unánimes de Rubén Dario; otras, con el regusto de un neofuturismo que, allá por los ochenta, llevó a recuperar la estética de los vértices, las hélices o las metrópolis de los vanguardistas; pero en ningún caso se me olvida la sonrisita socarrona de una jovencísima Ouka que, con un cochinillo por cimera, afirma ser la creadora de la mística doméstica, sintagma que compendia toda una diversidad de recursos literarios (por lo que tiene de similicadencia, de paronomasia, de oxímoron y de paradoja). A la larga o a la corta, la tradición es una vez más la clave (y desde estas líneas doy cuenta del tirón de oreja que me ha dado el editor del volumen, mi amigo Rafael Bonilla, por haber silenciado que el proparoxítono supone, antes de nada, un reto para el rimador, como nos recuerda Díez Rengifo en su Fertilísima silva de consonantes comunes, propios, esdrújulos...).

El peso ejercido por la tradición en la poesía de Ouka Leele tiene su correlato en el conjunto de su obra plástica, tanto en su fotografía como en su pintura, y por supuesto en las distintas mezclas o híbridos de una y otra. Hemos comenzado a entrever que siempre ocurre así, con independencia del tema que esté cultivando: urbanita, mitológico, fúnebre o hagiográfico. Exactamente lo mismo percibo en el bello mural de Ceutí, un encargo del Ayuntamiento de esa localidad murciana que atrapó a la artista durante dos largos años. Repárese en que tuvo que enfrentarse a casi trescientos metros cuadrados de pared. Imaginen los momentos previos al inicio de la tarea o vean, sin más, la película de Rafael Gordon, que apoya su relato en tan ardua empresa, que recoge de inicio a fin. ¡Cómo capta el horror vacui inicial de Ouka Leele! El necesario paso adelante lo da en el preciso instante en que escoge su color de fondo: el azul celeste.

El azul celeste y el blanco son los colores marianos por excelencia; además, su combinación resulta fundamental para representar el cielo en el arte de todos los tiempos. Por otra parte, el azul es el color de los ojos de Ouka Lee, única parte de su cuerpo que la artista transforma en materia 
poética, como en "Enredadera de la tormenta": "No te dabas cuenta de que el cielo me lloraba, con todas sus fuerzas. / ¿Tú no sabes que mis ojos son azules porque habitan en él / y mis lágrimas lloran desde allí, no desde mí?"; o como en "Cicatriz": "No mires, amor, mis ojos / ni su azul misterioso". En sus diversos tonos, el azul es también un color básico en los libros de horas o devocionarios iluminados, cuya consideración se me antoja primordial si se pretende comprender el mural de Ceutí. ¿A alguien le extraña que Ouka Leele se haya servido, precisamente, del más pálido y delicado de los azules? A estas alturas, creo que no.

En el arte de los libros de rezos del Medievo tardío y temprano Renacimiento, el elemento determinante es la flora. El uso recurrente de determinadas especies confirma que su presencia no es casual: están ahí porque las flores escogidas cuentan entre las más bellas de cuantas se conocen; están ahí, también, por el mensaje que muchas de ellas comportaban antes de que los primeros artífices de tan bellos libros decidiesen incorporarlas a sus miniaturas; están ahí, en fin, porque la cita pictórica acabó cuajando en una marca de género. Lo expresaré de otro modo: no hay libro de horas que no incluya una azucena, un gamón o el mucho más raro y bellísimo martagón (liliácea esta que, frente a la blancura intensa de sus dos parientes, presenta un naranja moteado); no hay libro de horas que no recoja la aguileña, la rosa, la margarita, la violeta o la fresa. Si de gradaciones se trata $-y$, en mi opinión, hay que marcarlas sin ningún género de duda-, el segundo término les corresponde al acónito, la peonía o alguna orquídea. Lo he dicho ya y lo digo de nuevo: el broche a este trabajo se lo pondrá mi breve pero reveladora colección de orquídeas europeas, una de las cuales adorna el Libro de Horas de Jean Bourdichon, códice francés de inicios del siglo XIV (British Library, Add, ms. 35214).

Por principio, los testigos vegetales escogidos se acompañan de algún que otro representante de una fauna modesta donde las haya, pues rara vez tienen cabida las aves y, menos aún, los mamíferos; por el contrario, se privilegian los invertebrados, como el caracol, el gusano y, sobre todo, la mariposa, que aparece machaconamente en las obras de esta índole. Es la misma mariposa que nos aguarda en el mural de Ceutí. Veamos algunos testigos de esta tradición que, en el caso de Ouka Leele, precisa del refuerzo de otros universos de referencia, como el de un Art Nouveau verdaderamente obsesionado por las mariposas, que cuajó en las artes 
suntuarias y decorativas (¿quién no recuerda las lámparas de Lalique inspiradas en este animalito?). Dejo estas últimas aparte para ofrecer unas cuantas piezas (son estas como pudieran ser otras) que llevan derechamente al mural de Ceutí:

En el mural, las únicas especies seguras (primera y cuarta por la izquierda) son la margarita y la rosa de Siria o hibisco siríaco. El resto es, básicamente, el resultado de lo que Ouka Leele recuerda haber visto en distintos lugares y de lo que precisa para que todo le cuadre en la composición; además, su marcada tendencia a la deformación antropomórfica, con un mucho de lúdicra, desvía a la artista desde el principio de la imitación de la naturaleza (cuya observancia, hoy más que nunca, o no se da o, de darse, nada tiene de estricta) al puro juego: véase, si no, cómo la especie de la derecha, que quiere parecerse lejanamente al martagón de los libros de horas, aunque también tiene mucho de estrella de mar, aparenta correr con los brazos abiertos y el cuello erguido. Por lo demás, a poco creemos ver una violeta o pensamiento; a poco, vemos también una gardenia, un clavel silvestre, un clavel reventón y una boraginácea (algo que no es de extrañar, pues la flor de la borraja, y especies afines, es de lo más común en los libros de horas). El centro le pertenece al as de oros, a un sol floral perfectamente apolíneo que nos recuerda a ranunculáceas como el botón de oro, aunque su tamaño diga en principio lo contrario.

Y no acaba ahí la cosa, como lo demuestra la comparación de la bordura vegetal que enmarca el conjunto con las que se adornan muchos de estos libros de rezos y otros de contenido fundamentalmente laico procedentes de escritorios italianos y de otros talleres de copistas del resto de Europa que siguen su pauta. Cuando de esto último se trata, lo normal es que el codicólogo, en sus descripciones, se sirva del genérico orla florentina, aunque este marbete, por lo mal que se viene usando, carece de cualquier precisión. Los ilustradores de los libros de horas y no pocos amanuenses tardomedievales recurrieron a figuras de tipo antropomórfico semejantes a las del mural murciano, que, según entiendo, bebe de varios veneros al mismo tiempo; sin embargo, en este caso la impronta parece proceder más de algunas escenas de Fantasía (1940) y otras películas de Walt Disney, pongo por caso, que de cualquier otra parte.

En la elección de especies, los libros de horas revelan, antes de nada, una voluntad estética muy marcada, en atención a su forma y color, sin 
perder de vista la relación que la especie de turno habrá de guardar con los demás elementos de la página. En los casos en que el artista pretende alguna manera de narratividad, importa mucho el orden o disposición de las especies seleccionadas; de ese modo, las escenas de la Anunciación se acompañan de la aguileña o planta del águila, que en neerlandés recibe el nombre de duiven ('palomas'), que a los artistas flamencos hubo de servirles, con seguridad, para aludir a la embajada del Espíritu Santo a la Madre de Dios. Por su parte, al lirio blanco o azucena, primera entre todas las plantas marianas, le conviene cualquier momento de la vida de la Virgen; por el contrario, el clavel se asocia con la Pasión de Cristo (lo que confirma la etimología de esta especie, cuyo nombre se justifica por el sorprendente parecido entre los clavos de gran tamaño y cuatro esquinas de otros tiempos y la mayoría de las variedades silvestres del dianthus) o a lo sumo, por influjo del franciscanismo tardomedieval, con la Natividad. Por lo dicho hasta ahora, queda claro que la función poética es el principio básico en el lenguaje artístico en general y no solo en la obra de arte literaria.

No tengo duda de que el mural de Ceutí, en su vertiente realista, pero mucho más en lo que tiene de fantástico, busca su apoyo primero, consciente o inconscientemente, en las ilustraciones de los libros de horas o devocionarios. Como ya he dicho, tanto en el fondo como en las figuras de los libros de horas, predominan los dos colores marianos por excelencia: el azul celeste y el blanco. Entre las flores blancas, hay azucenas y correhuelas; entre las azules más claras, sobresalen vincas, romeros, achicorias y verónicas, aunque también hay lugar para el azul fuerte de la aguileña, el jacinto, el anapelo o la borraja. Tampoco falta el color rojo, que en el Medievo se resuelve con una peonía, una rosa gálica (especie con asociaciones marianas y cristológicas), una digital purpúrea o una malva; en el caso del amarillo y el naranja, se oscila entre el jazmín silvestre, la prímula, la caléndula... Por supuesto, el verde aparece por doquier y en casi cualquier ubicación, aunque, como ya he dicho, es frecuente que los iluminadores recurran a hojas y tallos para construir cenefas o borduras.

La combinación de una flora predominante, con sus especies características, y una fauna apenas perceptible, en la que también imperan unas especies concretas, fraguó y dio en tradición. En su constitución, según entiendo, los copistas se dejaron llevar por una idea directriz: la de que 
un vergel era lo más parecido al paraíso que cabía imaginar en la tierra. Por eso, en zonas con agua abundante, tierras feraces, arboledas frondosas y rica flora fue donde buscaron su asiento la mayoría de los cenobios. Es la fórmula de San Antonio Abad, la de unos amantes de la vida en común que contrastan con los seguidores de San Pablo Protoeremita, que escogió el rigor del yermo en su deseo de acercarse a Cristo. En ese trabajo inminente a que ya he hecho referencia, daré cuenta de las especies que encontré en un paseo de no más de hora y media alrededor del antiguo monasterio de San Esteban, hoy Parador Nacional de la Ribera del Sil, y las que me salieron al paso durante otro paseo más, esta vez en torno a San Millán de la Cogolla.

Adelanto que, en el primer caso, encontré casi todas las especies que nos esperan en los libros de horas, y entiendo que no por casualidad. De todas las que fotografiamos en Galicia (lo de "fotografiamos" es un decir, pues las fotos las hicieron mi hija Carmen y mi amigo Argimiro Levoso), solo ofrezco una bellísima orquídea pálida, a la que siguen otras seis especies más de esta misma familia. De las fotos segunda a sexta (de bajísima calidad por haberlas tomado con un teléfono móvil de los más baratos), yo soy el único culpable; además, he hecho trampa en los casos segundo y tercero, pues he sustituido las fotos que tomé en La Rioja por otras dos que hice paseando con Carlos Alvar por el río Caslilla (Duruelo, Segovia). La última orquídea de la serie se la debo a mi hija Carmen, que la fotografió en el Cañón de los Almadenes (Cieza, Murcia), por lo que no guarda relación con ningún monasterio en concreto; si he decidido incluirla, ha sido pensando en los no iniciados, para que sepan que, incluso en los parajes más agrestes, al curioso le esperan sorpresas gratísimas.

¿Por qué destaco las orquídeas? Desde luego no por mero oportunismo o antojo, sino por su función en los libros de horas, particularmente en el caso de las orquídeas del género Ophrys, conocidas como "orquídeas abeja” y como "orquídeas avispa". Esa doble vinculación al reino vegetal y animal explica que aparezcan solas en el Libro de Horas Jean Boudichon, sin la preceptiva compañía de algún insecto alado. ¿Para qué, si ya lo llevan ellas consigo?. Veámoslas en el orden que he marcado antes:

Ya vigorosa, la vegetación de los libros de horas se infiltró sin dificultad en el espacio correspondiente al arte laico, como comprobé el año pasado en la exposición "Los amores de Mercurio y Herse. Una tapicería 
de Willem de Pannemaker (siglo XVI)", que logró reunir los ocho tapices dispersos desde 1909. Del conjunto, me interesó sobre todo el primer tapiz, procedente de la colección de la Duquesa de Alba, por ser el que más especies concentra; entre ellas, están varias de las más frecuentes en los libros de horas, lo que supone un caso claro de influjo del arte sacro sobre el arte laico o civil en su formulación más distante: la escena mitológica. Dado que no dispongo de una reproducción de calidad y no puedo centrarme en detalles, tan solo enumero las principales especies que alcancé a ver: acónito, fresa, correhuela, geranio, violeta, lúpulo y dedalera o digital purpúrea, todas ellas dispuestas a modo de cenefas o borduras.

¿Se precisa algún ejemplo más? Para los posibles escépticos, no me queda sino recordarles el retrato que Antonio Puccio Pissanello hizo de Margherita Gonzaga entre 1436 y 1440 (Musée du Louvre, París); en él, hay un fondo vegetal en que alternan dos especies de las que ya sabemos unas cuantas cosas: el clavel, asociado indefectiblemente a Cristo (y, en las estampas navideñas también a su madre), y la aguileña, estrechamente vinculada a las imágenes marianas, como ya he señalado. ¿Hay algo más digno de nota? Pues sí, debo resaltar -y si alguno de mis lectores ha buscado esta tabla en algún libro o en la propia web, ya habrá caído en la cuenta- el hecho de que ambas plantas se acompañan, de manera harto reveladora, de tres mariposas de especies diferentes. Como en el resto de los ejemplos aducidos, dejo su identificación a algún entomólogo avezado.

En la distancia, el estupendo mural murciano de Ouka Leele refleja lo a gusto que esta artista se encuentra cuando apela a la tradición. En este preciso sentido, su actividad plástica cuenta con el mismo estímulo que anima su labor poética. En sus versos, la orquídea ha encontrado ya su pequeño nicho; desde estas líneas, la animo a que indague maneras de incorporarla, junto a otras especies, a su fotografía, a su pintura o a cualquiera de las formulaciones artísticas en que apela a técnicas mixtas o híbridas. Los libros de horas le darán de nuevo la pauta; a cambio, ella sabrá cómo traerlos al presente. Para ello, procederá a uno de sus característicos aggiornamenti, ingeniosos y rompedores; al mismo tiempo, huirá del rancio revival como del mismísimo diablo. ¿Me darás ese capricho, querida Bárbara? 